\title{
Implementing Environmental Management Systems in a Cluster of Municipalities: A Case Study
}

\author{
Serena Botta and Claudio Comoglio \\ DIATI-Department of Environment, Land and Infrastructure Engineering, \\ Politecnico di Torino, C.so Duca Degli Abruzzi 24, 10129 Torino, Italy
}

Received 2013-08-26, Revised 2013-09-14; Accepted 2013-09-20

\begin{abstract}
Local authorities are showing an increasing interest in implementing Environmental Management Systems (EMS) according to ISO 14001/EMAS as a tool for better dealing with their environmental issues. However, to improve the status of an environmental component or the efficiency of an environmental service often exceeds the boundaries and the competences of a single municipality; furthermore EMS implementation can require significant human and financial resources which could not be faced by small organizations. In order to cope with the above problems a methodology for implementing an EMS in a cluster of municipalities is presented, with the aim of exploiting the possible synergies for sharing knowledge and resources and creating scaleeconomies to better deal with the environmental issues of the whole territory, both at cluster and at single municipality level. The proposed method was tested in a cluster of 33 small municipalities located in NW Italy, leading to the ISO 14001/EMAS certification of each organization. In this study the main methodological steps for implementing the proposed cluster approach and some significant outcomes of its application in the case study are presented.
\end{abstract}

Keywords: Environmental Management Systems, ISO 14001 and EMAS, Cluster Approach, Municipality, Local Sustainability

\section{INTRODUCTION}

Over the last years the implementation of Environmental Management Systems (EMS) according to ISO 14001 (ISO, 2004) and/or EMAS (EPC , 2009) is gaining an increasing interest by Local Authorities and Municipalities (in September 2012, $10.5 \%$ of the 4,525 EMAS registered organizations belonged to the sector "General public administration activities", NACE code 84.11 and was mainly located in Italy (261), Spain (92) and Germany (63) (EC, 2012)).

Initially designed for the industrial sector, an EMS can allow municipalities to better identify the environmental issues of their territory and to consequently plan and monitor environmental improvement objectives (Botta and Comoglio, 2007;
Quaglino et al., 2010; Petrosillo et al., 2012; Botta et al., 2013). Local authorities implement EMS in order to improve internal organization and deal more efficiently with local environmental issues (Emilsson and Hjelm, 2002; Daddi et al., 2011), with a particular focus on indirect aspects, i.e., those related to the activities and behaviours of citizens and other local stakeholders (Botta and Comoglio, 2007; Emilsson and Hjelm, 2007; Fahy and Cinneide, 2008; Marazza et al., 2010; Daddi et al., 2011; Petrosillo et al., 2012; Botta et al., 2013). In addition, the increased efficiency of the organization, especially if supported by transparency of information and citizens consultation (EPC, 2001; Emilsson and Hjelm, 2002; EPC, 2009; Botta et al., 2013) together with the obtainment of a prestigious environmental award (i.e., the certification/registration), can also lead to an improved political consensus for the local administration.

Corresponding Author: Serena Botta, DIATI-Department of Environment, Land and Infrastructure Engineering, Politecnico di Torino, C.so Duca Degli Abruzzi 24, 10129 Torino, Italy 
Thus recent studies discussing the benefits related to the adoption of EMS by municipalities still highlight the need for getting further evidences (Botta and Comoglio, 2007; Lozano and Valles, 2007; Quaglino et al., 2010; Daddi et al., 2011; Petrosillo et al., 2012; Botta et al., 2013), a spillover of beneficial effects on the entire municipality is recognized: e.g., an increased efficiency of the local environmental services (waste management, integrated water services, local transport, can lead to increased quality of life levels perceived by citizens (Botta and Comoglio, 2007; Lozano and Valles, 2007; Fahy and Cinneide, 2008; Quaglino et al., 2010; Petrosillo et al., 2012; Botta et al., 2013)).

However it must be outlined that some environmental issues can even significantly exceed the municipality's boundaries, involving a wider area and other public and private stakeholders (e.g., the ecological status of a watercourse or the management of the urban waste collection system); therefore, a single municipality, thus supported by an adequate EMS, can have a limited influence on the improvement of the related environmental conditions or performances. At the same time, the EMS implementation can require substantial human and financial resources and this can represent a significant limitation especially for small organizations (Frey and Iraldo, 2007; Zobel, 2007; Daddi et al., 2012; Granly and Welo, 2013).

The EMAS regulation proposes as a possible solution to overcome the above shortcomings the creation of networks of enterprises and a cluster approach in implementing the EMS, being a cluster defined as "group of independent organisations related to each other by geographical proximity or business activities jointly implementing the environmental management system" (EPC, 2009). This joint approach should aim to the registration of each organization from the cluster, while the EMS should be implemented "with the objective of avoiding unnecessary costs for participants, in particular for small organisations" (i.e., micro, small and mediumsized enterprises (EC, 2003) and local authorities governing less than 10,000 inhabitants (EPC, 2009)), which generally could face significant problems in implementing an EMS due to limited economical and human resources. This is the case of most of the Italian municipalities $(85.1 \%$ out of the 8092 municipalities have less than 10,000 inhabitants, while the 24.1 and $70.5 \%$ have respectively less than 1,000 and 5,000 inhabitants (ISTAT, 2011)).

While for the industrial sector some studies can be found in the scientific literature dealing with experiences carried out in clusters characterized by proximity (e.g., the Hackefors industrial district in Sweden, (Ammenberg et al., 1999)) or by common products (e.g., Lucca paper industry district in Italy, (Frey and Iraldo, 2007); four industrial districttextile, tannery, clothing and shoes in Tuscany, Italy, Daddi et al., 2012), no scientific research regarding clusters of municipalities is available. Significant cost savings compared to individual certifications were reported (Ammenberg et al., 1999; Frey and Iraldo, 2007) as well as improved legal compliance and environmental performances (Daddi et al., 2010), while the creation of a coordination group for the EMS implementation within the cluster (called "steering committee" in Ammenberg et al. (1999) or "promotion committee" in Daddi et al. (2012) and in Frey and Iraldo (2007)) was highlighted as a relevant element. The committee supported the members of the cluster in sharing resources and procedures and played both a coordination role, designing a support framework for implementing the EMS in all members organizations and a direct role, directly implementing some key steps of the EMS documentation, like the environmental policy and programme (Ammenberg et al., 1999; Frey and Iraldo, 2007).

The study was aimed at defining a methodology for implementing a similar cluster approach to a group of municipalities and to test effectiveness in a case study. In fact, through the cluster approach, the exploitation of the possible synergies among municipalities could lead to a better identification and management of the environmental issues of the territory both at cluster and at single municipality level (e.g., the state of the environmental components, the efficiency of environmental services, the compliance to applicable environmental laws); this joint implementation could create scale-economies and enforce the position of the municipalities in the relationships with contractors, organization providing environmental services (e.g., urban waste collection) and other stakeholders, trying to influence also the improvement of their environmental performances.

Therefore, the aim of this study was to define and test a possible methodology for implementing an EMS in a cluster of municipalities. The selected study site was a cluster of 33 small municipalities located in NW Italy where the proposed method was tested, leading to the ISO 14001/EMAS certification of each organization.

\section{MATERIALS AND METHODS}

The ISO 14001 standard (ISO, 2004) and the EcoManagement and Audit Scheme (EMAS) regulation (EPC, 
2009) were the basic reference documents used for the EMS implementation in the cluster of Municipalities.

The study site is a cluster of 33 small Municipalities located in NW Italy (Piedmont Region, Cuneo Province), belonging to a Local Action Group (EC, 2005) named Mongioie (L+ITPIE-006). Local Action Groups (LAGs) are made up of public and private partners from the rural territory and receive financial assistance from EU to implement local development strategies, by awarding grants to local projects.

The involved municipalities were: Alto, Bagnasco, Battifollo, Briga Alta, Briaglia, Caprauna, Castellino Tanaro, Castelnuovo di Ceva, Cigliè, Frabosa Soprana, Frabosa Sottana, Garessio, Igliano, Monasterolo Casotto, Montaldo Mondovì, Montezemolo, Niella Tanaro, Nucetto, Ormea, Pamparato, Paroldo, Priero, Priola, Roascio, Roburent, Rocca Cigliè, Sale San Giovanni, San Michele Mondovì, Scagnello, Torre Mondovì, Torresina, Vicoforte and Viola.

The cluster is characterized by:

- Spatial contiguity: All the municipalities are adjacent and the cluster forms an homogeneous area of $793.02 \mathrm{~km}^{2}$

- Small dimensions: The number of inhabitants of each municipality is between 48 and 3,432 (the 79\% has less than 1,000 inhabitants) while the number of employees ranges between 2 and 19 units (only two Municipalities have more than 10 employees)

- Territorial homogeneity: The municipalities are located in a piedmont area with a prevalent vocation for agriculture and rural activities (the most relevant activity in the area is agriculture, with large parts of the territory used for pastures and agricultural crops) and a common socioeconomic and cultural framework, with a potential for developing tourism based on local food products

- Similar distribution of settlements: The municipalities are mainly organized in a main center and several hamlets, with a consequent jeopardized distribution of residential areas, which affects the provision for environmental services

The first fundamental step of the study was the identification of clear roles and responsibilities within the cluster of municipalities, creating a coordination group representative of the different issues of the territory, that was called the "Cluster Environmental Committee". The chosen methodological approach, in good alignment with the ones described by Ammenberg et al. (1999); Frey and Iraldo (2007) and Daddi et al. (2012), was to define and elaborate the EMS key elements (e.g., Environmental
Review, Environmental Policy, EMS Manual) at cluster scale so that, in a later stage, each Municipality could adopt and integrate them with the analysis and management of its specific local issues.

Therefore, the following main elements of the EMS were defined and implemented by the Cluster Environmental Committee:

- Definition of roles and responsibilities

- Cluster Environmental Review

- Cluster Environmental Policy

- Cluster Environmental Programme

- EMS documentation and implementation (training and internal auditing)

- EMAS Environmental Statement

The implementation of each step was then carried out at single municipality level, under the coordination of the Committee (supported by external consultants), which provided specific guidelines on how to adapt and integrate the elements valid for all the cluster to local peculiarities (e.g., completion of the Environmental Policy with a section highlighting specific aspects and commitments of local relevance for the municipality).

The main steps of the methodological approach, highlighting the roles of the Committee and of each municipality, are shown in Table $\mathbf{1}$ and details of their implementation are described in the Results and Discussion section with reference to the more relevant outcomes from their application in the case study.

\section{RESULTS}

\subsection{Roles and Responsibilities}

The first fundamental step of the study was the identification of clear roles and responsibilities within the cluster of municipalities. With the proposed methodological approach, shared responsibilities defined at cluster level and a centralized coordination were considered necessary to overcome the organizational and economical limits of each organization. Therefore, a Cluster Environmental Committee was created as a coordination group representative of the different issues of each municipality: it was formed by the nominated EMS responsible of each of the 33 municipalities (mayors or delegates, mostly represented by the head of technical departments) and the President of the Mongioie Local Action Group acted as its chairman.

The main responsibilities assigned to the Committee by the municipalities of the cluster were: 
- Supply, at centralized and coordinated level, of specialist technical skills and expert knowledge not available in each organization

- Definition of the EMS implementation steps (Table 1) and coordination of the related activities

- Direct implementation of some key management phases of the EMS (environmental compliance evaluation, training, internal audit)

The Committee was appointed of the above responsibilities for both the first implementation phase and the maintenance of the certification over time, with the aim of creating a stable coordination structure which would minimize the organizational and economic efforts of each municipality.

The Committee identified as a key technical skill needed for the EMS implementation an adequate knowledge on the following topics:

- Environmental legal requirements applicable to municipalities

- Environmental issues of the territory

- ISO 14001 and EMAS

- Training skills (on environmental issues)

- Qualification for internal auditing

While skills on the first two issues were found within the Committee, external consultants were contracted in order to provide support with specific expert knowledge on EMS implementation and environmental training and auditing. Finally the Committee defined a scheme for calculating the percentage of the total implementation costs (mainly related to external consultants and to the certification body and to the implementation of the actions defined in the Environmental Programme) to be attributed to each municipality based on its number of inhabitants and territory surface.

\subsection{Environmental Review}

The identification of the significant environmental aspects within the Environmental Review is the first and one of the most important and complex step of the EMS implementation. The Committee, through specialist technical skills, provided through both experts members of the Committee and external consultants, compiled a first part of the Environmental Review containing data valid for the whole cluster and defined a specific guideline on how each municipality had to integrate the document with more specific and detailed information at local scale; this approach was aimed at setting a common and homogenous method in identifying and evaluating the critical environmental issues of the territory at both scales.
The main phases of the Environmental Review are described in the next paragraphs.

\subsubsection{Environmental Framework}

The main aim of this phase was the analysis of the state of each environmental component (e.g., air, water, soil, biodiversity) and of the related pressures and impacts due to human activities (e.g., infrastructures, industrial activities) carried out on the territory.

The environmental framework started at cluster scale, considering the whole territory under the competence of all the municipalities. The analysis was mainly based on the use of several national and regional databases and thematic maps and focused on the more sensitive areas (e.g., natural parks, Natura 2000 sites) and on the environmental components whose status resulted affected by human activities (e.g., contaminated sites, water abstractions). Afterwards, as specified in the guideline prepared by the Committee, each municipality carried out its local environmental framework by complementing the results of the cluster scale analysis with all the further sitespecific information and data already available at the competent technical departments (e.g., land planning data, previous environmental studies carried out for public works) even if only relevant to small portions of their territory.

\subsubsection{Municipality and Third Parties Activities}

Prior to the identification of the environmental aspects of an organization, its activities must be described and analyzed, evaluating operating procedures, responsibilities and level of management control. The competences of a municipality in terms of activities and services to be provided on the territory (e.g., water supply, waste collection) are defined by national laws regarding local authorities and are common for all the cluster, but each administration usually can independently decide how to manage them (e.g., directly, outsourced to a public consortium or to private contractors); therefore, the Committee supplied a general list and description of activities and services which fall under the competence of the municipalities, defining a classification method through which each organization had to specify in detail the following elements:

- Management typology: Direct (with its own personnel) or indirect (outsourced to third parties);

- Planning processes

- Operational procedures

- Infrastructures and equipment 
Serena Botta and Claudio Comoglio / American Journal of Environmental Science 9 (5): 410-423, 2013

Table 1. Methodological approach for implementing the EMS in the cluster of municipalities

\begin{tabular}{|c|c|c|}
\hline \multirow{2}{*}{$\begin{array}{l}\text { EMS } \\
\text { Steps }\end{array}$} & \multicolumn{2}{|l|}{ Roles and responsibilities } \\
\hline & Environmental committee & Municipalities \\
\hline \multirow[t]{11}{*}{ Env. Review } & \multicolumn{2}{|l|}{ Environmental framework: } \\
\hline & \multicolumn{2}{|l|}{ Analysis of the state of each } \\
\hline & environmental component at cluster scale; & framework with \\
\hline & & further site-specific information and data \\
\hline & \multicolumn{2}{|l|}{ Municipality and third parties activities: } \\
\hline & $\begin{array}{l}\text { List and description of common direct and out-sourced } \\
\text { activities; guidelines for analysis at local scale }\end{array}$ & $\begin{array}{l}\text { Application of guidelines at local scale } \\
\text { (procedures, infra-structures) related to direct } \\
\text { and outsourced activities }\end{array}$ \\
\hline & \multicolumn{2}{|l|}{ Environmental compliance evaluation: } \\
\hline & Identification of the main legal requirements and definition & Completion of the Environmental \\
\hline & of a preliminary Environmental Compliance Register & $\begin{array}{l}\text { Compliance Register with applicable } \\
\text { legal requirements at local level }\end{array}$ \\
\hline & \multicolumn{2}{|l|}{ Env aspects identification and significance evaluation: } \\
\hline & $\begin{array}{l}\text { Preliminary correlation activities-environmental aspects } \\
\text { (check-list); definition of significance criteria }\end{array}$ & $\begin{array}{l}\text { Completion of the activity-aspect checklists; } \\
\text { significance evaluation for the identified aspects }\end{array}$ \\
\hline \multirow[t]{3}{*}{ Env. Policy } & Definition of a draft Environmental Policy highlighting & Integration of the Env. Policy with further \\
\hline & commitments and Significant environmental aspects & specific commitments and aspects of local \\
\hline & of the cluster (from the Env. Review) & relevance; approval and communication \\
\hline \multirow[t]{2}{*}{ Env. Programme } & Definition and implementation of the & Approval and implementation of the Cluster \\
\hline & Cluster Environmental Programme & $\begin{array}{l}\text { Environmental Programme and integration } \\
\text { with further local env. Objectives }\end{array}$ \\
\hline \multirow[t]{10}{*}{ Management } & $\begin{array}{l}\text { Design of the EMS documentation: EMS Manual } \\
\text { (including operational procedures) and Annexes } \\
\text { (records format); definition of actions directly } \\
\text { carried out by the Committee; guidelines for integration }\end{array}$ & $\begin{array}{l}\text { Integration (based on guidelines) of the EMS } \\
\text { documentation with additional elements of local } \\
\text { relevance; formal approval of the EMS }\end{array}$ \\
\hline & $\begin{array}{l}\text { Definition of key environmental indicators and } \\
\text { operational guidelines for monitoring activities }\end{array}$ & Monitoring of key environmental indicators \\
\hline & Planning and centralized management of the & Attendance to training activities \\
\hline & Cluster Training Programme & \\
\hline & Planning and direct implementation of the & - \\
\hline & Cluster (internal) Audit Programme & \\
\hline & Support to municipalities in managing & Management of non-conformities (root cause analysis) \\
\hline & non-conformities & and implementation of corrective/preventive actions \\
\hline & Analysis of the reports of the & Implementation of the Management Review \\
\hline & Management Reviews of each municipality & \\
\hline \multirow[t]{4}{*}{ Env. Statement } & Definition of a common section of the & Completion of the municipality's \\
\hline & Environmental Statement and of the key & section and formal approval \\
\hline & elements and structure of the municipality's section & \\
\hline & \multicolumn{2}{|c|}{ Communication and dissemination of the Environmental Statements } \\
\hline
\end{tabular}

Table 2. List of the main municipalities activities and prevailing management typology

\begin{tabular}{lll}
\hline & Prevailing management typology & \\
Municipal activities and services & Direct & Indirect \\
\hline $\begin{array}{l}\text { Management of integrated water services } \\
\text { (water supply, sewerage, wastewater treatment) }\end{array}$ & & $\mathrm{X}$ \\
Waste management & $\mathrm{X}$ & $\mathrm{X}$ \\
Real estate management & & $\mathrm{X}$ \\
Public lighting & $\mathrm{X}$ & $\mathrm{X}$ \\
Management of municipal vehicles and equipment & $\mathrm{X}$ & $\mathrm{X}$ \\
School transport service & & $\mathrm{X}$ \\
Management of school canteens & $\mathrm{X}$ & $\mathrm{X}$ \\
Management of green areas & $\mathrm{X}$ & $\mathrm{X}$ \\
Management of municipal roads & $\mathrm{X}$ & $\mathrm{X}$ \\
Inspections on the territory & & \\
Office activities & & \\
\hline
\end{tabular}


For the outsourced activities, each municipality had to describe the level of its management control on the contractor performances in order to identify potential for further improvements (e.g., increased controls and audits, contract revision introducing more stringent environmental requirements).

In Table 2 the general list of the main activities identified for all the municipalities of the cluster is presented, highlighting the prevailing management typology (direct/indirect) identified in the case study.

It must be outlined that in the cluster several relevant environmental services, like the management of integrated water services and waste management are mainly outsourced and in some cases this is required by law. For the waste management a regional law defined large homogeneous areas in which the municipalities had compulsorily to join a public consortium responsible of planning, managing and monitoring the urban waste cycle; the municipalities participate as members, keeping a decision-making role in the planning and control of this environmental service. Thanks to this management typology, the Committee directly collected from the consortium detailed information and relevant data characterizing the service with regards to each municipality, allowing to more easily compile this part of the Environmental Review. On the other hand the analysis of the activity "management of integrated water services" was particularly complex, especially with regards to the infrastructures and related authorizations and monitoring data; in fact the jeopardized distribution of residential areas, which characterizes the cluster, resulted in an high number of different infrastructures for the water supply and wastewater treatment.

This element, along with a wide variety of management typologies (mainly outsourcing to contractors defined by different local consortia), required intensive work in gathering data from different sources and in analyzing and organizing a relevant amount of information for each municipality (authorizations, wastewater treatment plants operation schemes, chemical analyses, quantitative monitoring data). The activity "inspections on the territory" was related to the direct competence of the municipality in monitoring possible critical instances of non-compliance with environmental legislation (e.g., abandoned waste, contamination of water) due to activities carried out by third parties (considering citizens, local enterprises and other local stakeholders). For this purpose, within the Environmental Review the Committee identified all the main activities (and related plants and infrastructures) carried out in the territory of the cluster which can have relevant environmental impacts; among these, the following were outlined: industrial plants subject to IPPC Directive (EC, 2008), combustion plants for energy production, hydropower plants, waste treatment plants and landfills, quarries, intensive farming, tvradio-telephone transmission systems, ski resorts and tourist accommodation services. Therefore, every municipality analyzed for each of the activities carried out on its territory the level of control and influence that it operated on the third party and the availability of related environmental data (e.g., results of the periodical monitoring of emissions to air and/or discharges to water as required by authorizations and permits). The analysis was directly carried out by the Committee when the activity of a third party involved the territory of more than one municipality (as in the case of waste management).

\subsubsection{Environmental Compliance Evaluation}

Full compliance with applicable environmental laws is one of the key requirements of EMS, which has to be maintained over time by periodical evaluations defined by specific operational procedures.

The Committee, based on the activities and competences of the municipalities of the cluster, carried out a preliminary identification of all the applicable environmental laws, listing all the related requirements and records needed to demonstrate full compliance. For each municipality a preliminary Environmental Compliance Register was then defined, containing:

- Applicable environmental laws

- Related legal requirements, with control deadlines and frequencies

- Records needed to demonstrate full compliance

The Register was then completed and integrated with the available information by each municipality, through the support of the external consultants, which collected all the related records creating a specific electronic archive to be continuously updated.

\subsubsection{Environmental Aspects Identification And Significance Evaluation}

For each of the activities/services identified in the list (Table 2) the Committee defined at cluster level a preliminary correlation to the most frequent related environmental aspects, referring to the set specified by EMAS (EC, 2008): Emissions to air, releases to water, waste production and management, use and 
contamination of land, use of natural resources, energy and raw materials, local issues (noise, vibration, odour, dust, visual appearance), transport issues (both for goods and services and employees), possible environmental risks related to incidents, accidents and potential emergency situations and effects on biodiversity. For each aspect, a checklist highlighting the more relevant information needed to adequately describe the correlation activity-aspect was prepared and partially fulfilled with the information already available from the previous steps of the Environmental Review, so that each municipality could more easily complete the analysis with further detailed data collected at local level. The general significance criteria were established at cluster level in order to have an homogeneous evaluation by all the municipalities and were referred to four main issues related to each environmental aspect:

- Potential for compromising sensitive environmental components

- Ability to keep the compliance with environmental laws

- Complaints/reports/pressures from stakeholders

- Need for improving the knowledge of the aspect

The evaluation method defined at cluster level was applied independently by each municipality, which in this way identified the more significant aspects related to its activities and to those carried out by third parties on its territory; the register of significant aspects obtained by each municipality was then submitted to the Committee for a final review. Finally, the Committee evaluated the aspects to be considered significant at cluster level (i.e., those identified as significant by a relevant number of municipalities), to be subsequently considered when defining the Cluster Environmental Programme.

\subsection{Environmental Policy}

The Environmental Policy documents the willingness of each organization to implement the EMS and its commitment to a continuous environmental improvement.

In the cluster approach it was considered relevant to highlight that the commitment of the municipality belonged to a common strategy shared among local authorities of the same area. For this reason the Committee elaborated a draft Environmental Policy structured into two sections:

- A common one which outlined the shared commitment of all the municipalities to cooperate with the other members of the cluster for the continuous environmental improvement of the territory

- A second section, presenting the main environmental commitments of the cluster, based on the improvement of the most significant environmental aspects that characterized the territory as revealed during the Environmental Review, with a final part that could be integrated by each municipality listing further specific commitments autonomously decided at local level

Every Mayor was then requested to formally approve and sign the final document completed on the basis of the cluster draft, enforcing the related commitments from a legal and political point of view. The documents were then communicated by each municipality to their employees during training activities and to the public, with a particular focus on citizens (through the municipalities websites, letters to the residents and public information meetings) and suppliers (the compliance to the Environmental Policy basic principles, along with applicable operational instructions of the EMS, became a compulsory requirement).

\subsection{Environmental Programme}

On the basis of the Environmental Review outcomes, with particular regards to the environmental aspects which were evaluated as significant by a relevant number of municipalities, the Committee defined a Cluster Environmental Programme, aimed at achieving a set of objectives (based on a duration of three years) which were characterized by the following factors:

- Addressing the needs of the largest number of municipalities: Each objective should be related to common issues and lead to environmental improvements in most municipalities of the cluster

- Creating scale-economies: The costs needed for achieving the objective should be lower at cluster scale compared to implementation by each individual municipality

- Being more feasible if carried out at cluster scale: To be achieved by means of technical and organi zational resources not available at single municipality level

- Improving the beneficial effects on the environment thanks to an implementation at wider scale

- Influencing the behavior of local stakeholders: The improvement of the environmental performances should not be limited to local authorities but also 
related to environmentally relevant activities carried out by third parties on the territory

A preliminary draft of the Cluster Environmental Programme was issued and discussed within the Committee in order to get a preliminary approval and to identify the roles of each member in the objectives implementation. Therefore, for each action related to each objective the following elements were defined: the overall costs and the cost for each municipality, the role of each municipality in implementing the action (highlighting possible leaderships or particular roles), the deadlines and indicators for monitoring their completion. The consultation phase with all the municipalities represented a key-step that allowed to define objectives shared by all the members of the cluster, thus ensuring an adequate commitment for achieving the planned targets, also sharing related costs. Every Mayor was then requested to formally approve and sign the final document of the Cluster Environmental Programme.

Among the several objectives of the Programme the following ones can be highlighted, which include actions to be carried out to improve the environmental performances of the municipalities and the local stakeholders:

- Improving the energy consumption monitoring systems and increasing the use of renewable energy sources in public buildings

- Implementing an energy efficient public lighting (photovoltaic panels)

- Incrementing the percentages of separate urban waste collection above $65 \%$

- Incrementing the percentages of green public procurement

- Definition of a regulation (at cluster level) for restructuring buildings and architectural heritage based on energy saving and GHG emission reduction techniques

- Training and technical assistance to local farmers and forestry sector operators on green technologies for reducing environmental aspects and GHG emissions (and promotion of local products)

- Training and technical assistance to accomodation structures on green tourism and Ecolabel

The Environmental Programme of each municipality was then a document signed by the Mayor and formed by all the objectives of the Cluster Environmental Programme, by highlighting the roles, resources and deadlines attributed to the individual local authority; in addition each municipality listed further specific objectives autonomously decided at local level, to be completed by using own resources.

\subsection{EMS Documentation and Implementation}

The documentation structure of the EMS was defined by the Committee in a simplified way, by removing one level of the EMS documentation structure, the procedures/instructions one, keeping only the manual and the records (in addition to Environmental Policy and EMAS Environmental Statement): the Committee defined a comprehensive EMS Manual including in each of its sections, in a schematic way, the specific operational actions needed for ensuring the effective planning, operation and control of processes related to the EMS implementation in compliance with ISO 14001/EMAS requirements. Where applicable, the reference formats for the related records (e.g., training records, energy consumption monitoring tables) were provided as annexes to each section of the Manual.

Furthermore, in order to simplify the use of the Manual and related records by each municipality, the different roles and responsibilities assigned to the cluster and to the municipality were clearly outlined in each section. The main tasks assigned to the Environmental Committee were related to:

- Environmental Review update

- Identification of applicable legal requirements and periodical compliance evaluation

- Management and control of the Cluster Environmental Programme

- Planning and management of environmental training

- Planning and management of environmental audit

The other sections of the Manual were provided in form of specific guidelines through which each municipality had to implement the EMS. For example, the Operational control section defined the specific actions to be carried out (and related records to be fulfilled) in relation to the activities characterized by the most common significant environmental aspects identified during the Environmental Review; specific operational guidelines were provided for the management and monitoring of the environmental aspects related to: Management of integrated water services, waste management, real estate management, management of municipal roads, inspections on the territory. According to the data and information analyzed in the Environmental Review, a set of indicators related to the key environmental areas was defined (Table 3), to be monitored by the municipalities at fixed intervals, using reference records annexed to the Manual and then reported in the annual EMAS Environmental Statement. 
Table 3. Main environmental indicators set

\begin{tabular}{|c|c|}
\hline Key environmental areas & Indicator \\
\hline \multirow[t]{8}{*}{ Energy efficiency } & Electricity consumption in public buildings (kWh) \\
\hline & Electricity consumption in public buildings/surface $\left(\mathrm{kWh} / \mathrm{m}^{2}\right)$ \\
\hline & Fuel consumption for heating in public buildings $\left(1 \mathrm{or} \mathrm{m}^{3}\right)$ \\
\hline & Fuel consumption for heating in public buildings/surface $\left(1 / \mathrm{m}^{2}\right.$ or $\left.\mathrm{m}^{3} / \mathrm{m}^{2}\right)$ \\
\hline & Efficiency of heating systems $(\eta)$ \\
\hline & Fuel consumption for transport (1) \\
\hline & Fuel consumption for transport/distance driven $(1 / \mathrm{km})$ \\
\hline & Total consumption (GJ) \\
\hline \multirow[t]{6}{*}{ Water } & Water consumption $\left(1\right.$ or $\left.\mathrm{m}^{3}\right)$ \\
\hline & Water consumption/ number of employees $\left(1 / \mathrm{n}^{\circ}\right.$ or $\left.\mathrm{m}^{3} / \mathrm{n}^{\circ}\right)$ \\
\hline & Number of not conforming analysis on wastewater/ number of analysis (after treatment) (\%) \\
\hline & Mean value of $\mathrm{BOD}_{5}$ in wastewater (after treatment) $\left(\mathrm{mg} / \mathrm{m}^{3}\right)$ \\
\hline & Mean value of COD in wastewater (after treatment) $\left(\mathrm{mg} / \mathrm{m}^{3}\right)$ \\
\hline & Mean value of TSS in wastewater (after treatment) $\left(\mathrm{mg} / \mathrm{m}^{3}\right)$ \\
\hline \multirow[t]{2}{*}{ Material efficiency } & Consumption of recycled paper/total consumption of paper $(\%)$ \\
\hline & $€$ spent for green products/total expenses (\%) \\
\hline \multirow[t]{5}{*}{ Waste } & Weight of total waste produced $(\mathrm{t})$ \\
\hline & Weight of recycled waste $(t)$ \\
\hline & Weight of hazardous and non hazardous waste $(\mathrm{t})$ \\
\hline & Weight of produced waste/number of inhabitants $\left(t / n^{\circ}\right)$ \\
\hline & $\%$ of separate collection $(\%)$ \\
\hline Emissions & Total emissions of $\mathrm{CO}_{2}(\mathrm{t})$ \\
\hline \multirow[t]{2}{*}{ Biodiversity } & Total surface occupied by protected areas $\left(\mathrm{m}^{2}\right)$ \\
\hline & Builtup area $\left(\mathrm{m}^{2}\right)$ \\
\hline
\end{tabular}

Furthermore, basic guidelines were supplied in order to integrate the Manual with additional operational control and monitoring actions in case that a municipality had uncommon activities with environmental relevance: This was the case of two municipalities of the cluster that had a ski resort in their territory and one that managed a biomass plant supplying heating to households.

The EMS Manuals completed by each municipality according to their own specific characteristics and in compliance to the provided guidelines, were then reviewed at cluster level by the external consultants and, after some final adjustments, formally approved by each Mayor on behalf of the City Council.

Training activities in an EMS play a key role: The organization must identify training needs associated with its environmental aspects and its EMS, guaranteeing that any person performing tasks that have the potential to cause a significant environmental impact is competent on the basis of appropriate education and training. The cluster approach allowed an optimization of this process, since the Committee was in charge of identifying the common training needs for the EMS implementation and of organizing the related training activities (through external consultants), defining a Cluster Training Programme. Training activities were mainly carried out in a centralized way, with common sessions for trainees from all the municipalities (every municipality had to identify which of its employees had to attend the different sessions according to their roles and tasks). The main efforts in the initial phase were devoted to carry out training activities on the key concepts of ISO 14001/EMAS and on the implementation of the actions defined in the EMS Manual; in a second phase, specific training was provided on the compliance to applicable environmental laws and on the management of all the records related to the different operational sections of the EMS Manual.

A similar approach was used for another key element of the EMS implementation, the internal audit: The Committee defined a Cluster Audit Programme to be carried out by qualified external personnel (a team of six auditors) on each municipality, in order to check the EMS implementation in a homogeneous, independent and qualified way. The Committee coordinated the conduction of audit activities in each municipality, acting as an interface between the audit team and the municipality (planning dates, communicating scope and methods). The audit reports, with findings and nonconformities, were then submitted to the municipality and to the Committee; then the municipality had to carry out the rootcause analysis of each finding and, where applicable, to define corrective and preventive actions, 
with the technical support of the Committee, where needed. The results of such evaluation were submitted to the Committee, which analyzed the main critical issues of each municipality (common non-conformities or potential criticalities in law compliance) in order to identify possible improvement actions to be implemented, for example, through additional objectives of the Cluster Environmental Programme or further training activities.

The management review, final phase of the EMS implementation aimed at ensuring the internal audit results and EMS suitability, adequacy and effectiveness, was carried out separately at each municipality, involving the Mayor and the City Council, on the basis of the guidelines and reference records provided in the specific section of the EMS Manual. Comments and decisions related to possible changes to environmental policy, objectives, targets and other elements of the EMS, consistent with the commitment to continual improvement, were recorded on a specific report, signed by the Mayor and submitted to the Committee. The management review reports of all the municipalities were then reviewed by the Committee in a plenary session (involving all the Mayors of the cluster), that evaluated all the consistent recommendations for improving the EMS at cluster level and planned the related actions, defining resources and responsibilities.

\subsection{EMAS Environmental Statement}

EMAS Regulation requires registered organizations to provide the public with validated and comprehensive information on its EMS and related environmental performances through the Environmental Statement. Therefore, the Committee prepared a draft scheme of this document to be adopted and integrated by each municipality, in order to achieve an individual registration. The EMAS Environmental Statement scheme was structured in two parts:

- A common part, valid for each municipality, in which the methodological approach used for the cluster implementation was presented, highlighting the main elements of the EMS and citing all the municipalities of the cluster in order to allow the public to have access to environmental data of the whole territory

- A specific part to be compiled by each municipality, in compliance with EMAS requirements, highlighting the specific individual elements of the EMS at local level (e.g., details of applicable legal requirements, copy of the Environmental Policy, municipality's performance data and indicators)
The data related to the environmental indicators of Table 3 were presented highlighting, where available, performance trends on a three years basis: this choice was aimed at defining some common thresholds of environmental performances to be adopted in the next future for the definition of more ambitious environmental objectives of continuous improvement. The Environmental Statement prepared by each municipality was submitted in draft to the Committee for a compliance check and then formally approved during the management review by the Mayor and the City Council.

\subsection{Certification Process}

The cluster approach was used also in the identification of the certification body: it was chosen by the Committee for all the municipalities based on documented experience in the local authorities sector and on the provision of a skilled audit team that would inspect all the municipalities with uniform criteria. The certification body defined an audit team that carried out the certification audit in all the municipalities of the cluster. An important part of the audit process was related to the roles and responsibilities of the Committee and the EMS documentation structure. Specific operational surveys were then carried out in each municipality, with a specific focus on how the EMS was implemented at local scale. This choice, apart from guaranteeing an homogeneous evaluation of the EMS implemented with the cluster approach, allowed to minimize the time needed for checking the common elements of the EMS directly managed by the Committee and, thus reaching certification/registration on individual basis, significantly reduced (around 60\%) the related costs. The Environmental Statements of the municipalities applying for EMAS registration were presented to the certification body for validation and then, to the National competent body for activating the individual registration procedures.

The whole project started in June 2006 and the certification audits took place between December 2007 and May 2008. In 2008 all the 33 municipalities obtained the ISO 14001 certification, while 15 of them also had their EMAS Environmental Statement validated and were later listed in the EMAS register by the National competent body. The main problem that prevented several municipalities from moving to EMAS was related to the management of integrated water services: a recent regional law transferred the ownership of the authorizations (wells, springs, discharges to water) to three local consortia in the cluster and this caused 
significant delays in reissuing the legal documentation of a large number of small infrastructures; with this formal lack of full legal compliance by a contractor, the National competent body did not allow the EMAS registration of the interested municipalities.

The ISO 14001 certification and EMAS registrations were maintained by all the municipalities of the cluster until May 2013, when 11 municipalities, after having solved the above problems, obtained the EMAS registration and 4 municipalities obtained the validation of their EMAS Environmental Statement and are now facing the registration process, that will soon increase the total number of EMAS registered organizations to 30 municipalities ( $91 \%$ of the cluster).

\section{DISCUSSION}

The proposed cluster approach tested in the case study allowed to overcome the difficulties often encountered by small organizations while implementing an EMS, mainly due to a lack of human and financial resources; through a technical and decisional coordination at central level, the clear definition of roles and responsibilities on which the study was based allowed a faster and more effective development of the main activities foreseen by ISO 14001 and EMAS, providing to all the members of the cluster a simple and clear framework for implementing each step of the EMS. In the case study the Cluster Environmental Committee, in which each municipality was represented, had a key role both in the first implementation phase and in the EMS maintenance over time. In particular, the key choice was to allocate to the Committee relevant tasks like the direct implementation of some significant actions (e.g., environmental compliance evaluation, training, internal auditing) and the provision to all the members of the cluster of specialist skills not available in each organization. Therefore, such a coordinating entity has to be considered fundamental for implementing a cluster approach. However its establishment can represent a complex issue since it requires a clear agreement among several institutions that could often be led by different political parties and may have a narrower vision limited within their own boundaries; in the case study, since all the municipalities belonged to a Local Action Group aimed at jointly implementing local development strategies, these problems were limited and the agreement on defining the role of each municipality of the cluster in decisionmaking and financial contributions was quite easily found.

Among the most complex and timeconsuming issues identified during the project, the data collection for the
Environmental Review has to be outlined; the creation of a cluster database of environmental data required a preliminary identification of a wide variety of sources (mainly institutional databases) which were fragmented and with limited access and the consequent elaboration and reorganization of a huge amount of data related to the different environmental components. Through the proposed approach, the environmental framework was carried out by the Committee at cluster scale and then complemented by each municipality with sitespecific information: this contributed to an improved knowledge of the environmental data available on that area and to the identification of the main critical issues that characterized the territory; furthermore, it allowed to deal with problems exceeding each municipality's competences, expanding the view beyond the local boundaries and led to the identification and planning of improvement objectives with responsibilities and resources shared among the cluster members.

During the analysis of the activities carried out by contractors (i.e., indirect environmental aspects), the identification of the current levels of control/influence operated by each municipality revealed to be a keyfactor since it allowed to identify the potential for requiring/influencing the third party towards a future improvement of its environmental performances. The potential for such an increased control/influence was even higher where the relationships with the contractor were shared among several municipalities of the cluster (e.g., with companies providing environmental services to several municipalities, like waste management, integrated water services) that, now triggering the ISO14001-EMAS certification, can jointly have a more relevant weight in redefining terms and conditions of the service, obtaining an updated and continuous flow of relevant information regarding legal compliance and environmental monitoring data. The same applied when dealing with other companies operating on the territory (i.e. not municipalities' contractors), from which a more transparent flow on information related to their environmental performance was progressively obtained.

During the Environmental Compliance Evaluation phase some criticalities were found, often highlighting similar non-conformities in several municipalities, mainly related to a limited knowledge of the environmental legislation (which is particularly complex and continuously evolving) due to a lack of specialist skills among the personnel of these small municipalities. The method used for the environmental compliance evaluation represented a significant strength of the cluster approach, with the Committee supporting each 
municipality in identifying non-conformities, providing advice for restoring full compliance. The Commitee also acted as a coordination point for updating all the municipalities with regards to revisions or new issue of applicable laws and for alerting on the deadlines related to periodical obligations (e.g., heating systems controls, chemical analyses of releases to water), thus relieving them from the need for autonomous update (complex and burdensome task for small municipalities). Furthermore, by identifying common compliance problems, the interested municipalities were able to jointly refer to the competent authorities (Region, Province, Environmental Agency) or other third parties in order to achieve a shared actionplan for a faster and more efficient solution of the criticalities. Furthermore, the Cluster Environmental Programme was highly appreciated and endorsed by these institutions, that acknowledged how these shared targets planned and implemented by the cluster can be beneficial for the whole territory at a wider scale than at single municipality's level. In fact, the joint definition and pursuit of common environmental objectives represent one of the most effective and promising results of the cluster approach: the actions aimed at solving environmental problems at cluster level identified during the Environmental Review, with clearly defined responsibilities and resources shared among the municipalities, required lower costs (in some cases the cluster was also able to raise also external funds due to the relevance of the objectives), employed better technical and organizational resources and determined more beneficial effects compared to their alternative implementation by each individual municipality.

The coordination role of the Committee was continued throughout the implementation of each step of the EMS, whose documentation structure was simplified with the aim of limiting the related bureaucracy (i.e., to reduce the number and extent of procedures, instructions and records while allowing an adequate control of the significant environmental issues) and of supplying a simple scheme that could be easily adopted by each municipality. Thanks to this approach the results of the case study outlined that that even very small municipalities were able to improve the efficiency of their institutional role and actions in safeguarding the environment: the simplification of the EMS structure (the manual includes operational procedures) and the coordination at central level (through the Cluster Environmental Committee and its external consultants) of the main actions for implementing the EMS, revealed to be fundamental; in particular, the definition of a common structure valid for all the municipalities and the provision of guidelines addressing each member of the cluster to adapt the EMS to its local characteristics, together with the direct implementation by the Committee of several fundamental actions (e.g., Environmental Review, training, internal auditing) allowed an efficient implementation of the ISO 14001/EMAS requirements in every municipality.

The cluster approach allowed a significant cost reduction if compared to the organizational and financial resources that would have been needed for implementing a similar EMS on an individual basis in each municipality of the cluster and in particula this applies to the Environmental Review (especially in relation to legal compliance evaluation), the Environmental Programme (starting common improvement actions at wider scale), the internal training and auditing and the certification process.

Despite the several positive outcomes of the cluster approach presented in this study, some limitations about its representativeness can be highlighted. The first one, already mentioned before, is that it requires that several local authorities operating in an homogeneous territory have common objectives of environmental safeguard and agree on forming a cluster, sharing resources and responsibilities and this willingness could often be affected by several factors, such as localism, politics. In this study the presence of a Local Action Group allowed to easily overcome this problem. Another limit can be represented by the small size of the municipalities that were considered, which is a characteristic feature of Italian local authorities (very small organizations with a limited number of inhabitants). Even if this can not be representative of many other countries, the fact that the cluster approach was successful means that with a common vision and shared efforts even small organizations can implement an EMS and achieve environmental improvements. In any case, even the smallest municipality has the same institutional competences (e.g., provision of environmental services) of the bigger ones and therefore, it can be assumed that even a cluster of larger municipalities, having more resources and same tasks of the smaller ones, could also achieve better results from implementing the proposed joint approach.

Finally, it has to be outlined that, while the design and startup of the project was based on funds obtained from EU by the Local Action Group (these resources allowed the initial implementation of the EMS until the first certification audits), the maintenance of the systems and the annual update/renewal of certifications/registrations was and still is, selffunded by 
each municipality based on its own institutional budget, contributing on annual basis according to the costs foreseen by the Committee (e.g., for the external consultants, for the certification body, for implementing the objectives of the Environmental Programme) and this continuity of commitment in the EMS provides further evidence to the strength of the proposed methodology.

\section{CONCLUSION}

In this study the main outcomes of a casestudy, where an innovative cluster approach for implementing an EMS according to ISO 14001 and EMAS requirements was tested in a group of 33 small Italian municipalities, are presented. The proposed methodology revealed to be successful since all the municipalities obtained the ISO 14001 certification (and most of them also the more complex EMAS registration) and maintained it over the following years.

The cluster approach allowed to analyze in a uniform and comprehensive way the environmental issues of the territory both at cluster and at single municipality level, sharing knowledge and resources among cluster members, creating scale-economies that led to a significant costs reduction and enforcing the position of the municipalities in the relationships with relevant stakeholders. The coordination at central level of the EMS implementation and the direct involvement and consequent commitment of all the participating municipalities were fundamental drivers of these positive outcomes and must be considered as fundamental elements needed for a successful implementation of any EMS implementation at cluster level.

Therefore, it can be stated that the proposed methodology tested in the case study can represent a useful and innovtive reference for all the local authorities willing to implement and EMS, going beyond their local boundaries in order to target shared environmental objectives at a wider scale, exploiting the synergies with neighboring municipalities in a common effort to improve the environmental safeguard of their territory.

\section{REFERENCES}

Ammenberg, J., B. Borjesson and O. Hjelm, 1999. Joint EMS and group certification: A cost-effective route for smes to achieve ISO 14001. Greener Manage. Int., 28: 23-31.
Botta, S. and C. Comoglio, 2007. Environmental management systems in local authorities: The case study of the cesana torinese municipality, a Turin 2006 Olympic site. Am. J. Environ. Sci., 3: 126-134. DOI: 103844/ajessp.2007.126.134

Botta, S., C. Comoglio and I. Petrosillo, 2013. Implementing the environmental and social policies of a municipality through an integrated management system: Theoretical framework and case study. J. Environ. Plann. Manage., 56: 1073-1095. DOI: 10.1080/09640568.2012.743881

Daddi, T., F. Testa and F. Iraldo, 2010. A cluster-based approach as an effective way to implement the environmental compliance assistance programme: Evidence from some good practices. Local Environ., 15: 73-82. DOI: 10.1080/13549830903406081

Daddi, T., M. Frey, F. Iraldo and B. Nabil, 2011. The implementation of an environmental management system in a Northafrican local public administration: The case of the city council of marrakech (Morocco). J. Environ. Plann. Manage., 54: 813832. DOI: $10.1080 / 09640568.2010 .537543$

Daddi, T., M.R. De Giacomo, F. Testa and S. Tessitore, 2012. Cluster approach and ecoinnovation in four industrial clusters of Tuscany region (Italy). Environ. Econ., 3: 26-34.

EC, 2003. Recommendation 2003/361/EC concerning the definition of micro, small and mediumsized enterprises. European Commission, Brussels, Belgium.

EC, 2005. Regulation (EC) No 1698/2005 on support for rural development by the European Agricultural Fund for Rural Development. European Council, Brussels, Belgium.

EC, 2008. Directive No 2008/1 concerning integrated pollution prevention and control. European Commission, Brussels, Belgium.

EC, 2012. Statistics and Graphs. EMAS European Commission.

Emilsson, S. and O. Hjelm, 2002. Implementation of standardised environmental management systems in Swedish local authorities: Reasons, expectations and some outcomes. Environ. Sci. Policy, 5: 443-448. DOI: 10.1016/S1462-9011(02)00090-4

Emilsson, S. and O. Hjelm, 2007. Managing indirect environmental impact within local authorities' standardized environmental management systems. Local Environ., 12: 73-86. DOI: $10.1080 / 13549830601098271$ 
EPC, 2001. Regulation (EC) No 761/2001 allowing voluntary participation by organisations in a Community Eco-Management and Audit Scheme (EMAS). European Parliament and Council, Brussels, Belgium.

EPC, 2009. Regulation (EC) No 1221/2009 allowing voluntary participation by organizations in a Community Eco-Management and Audit Scheme (EMAS). European Parliament and Council, Brussels, Belgium.

Fahy, F. and M.O. Cinneide, 2008. Developing and testing an operational framework for assessing quality of life. Environ. Impact Assess. Rev., 28: 366-379. DOI: 10.1016/j.eiar.2007.10.001.

Frey, M. and F. Iraldo, 2007. A Cluster-based approach for the application of emas. MAIN Working Paper Series. Bocconi University.

Granly, B.M. and T. Welo, 2013. EMS and sustainability: Experiences with ISO 14001 and Eco-Lighthouse in Norwegian metal processing SMEs. J. Cleaner Product. DOI: 10.1016/j.jclepro.2013.08.007

ISO, 2004. ISO 14001 Environmental Management Systems-Requirements with guidance for use. ISO, Canada Standards Association.

ISTAT, 2011. Population and Housing Census.
Lozano, M. and J. Valles, 2007. An analysis of the implementation of an environmental management system in a local public administration. J. Environ. Manage., $\quad 82$ : 495-511. DOI: 10.1016/j.jenvman.2006.01.013

Marazza, D., V. Bandini and A. Contin, 2010. Ranking environmental aspects in environmental management systems: A new method tested on local authorities. Environ. Int., 36: 168-179. DOI: 10.1016/j.envint.2009.10.011

Petrosillo, I., A. De Marco, C. Comoglio and S. Botta, 2012. EMAS in local authorities: Suitable indicators in adopting environmental management systems. Ecol. Indicators, 13: 263-274. DOI: 10.1016/j.ecolind.2011.06.01

Quaglino, A., S. Botta, A. Torchia and C. Comoglio, 2010. Environmental management systems and municipal solid waste management in Local Authorities. GEAM: Geoingegneria Ambientale Mineraria, 1: 25-32.

Zobel, T., 2007. The 'pros' and 'cons' of joint EMS and group certification: A swedish case study. Corporate Social Responsib. Environ. Manage., 14: 152-166. DOI: $10.1002 /$ csr. 125 